\title{
WHO warns European countries to be on alert for Zika
}

\author{
Anne Gulland
}

London

European countries need to be on the alert for the Zika virus and act to control it now, the World Health Organization has urged.

In a statement released on 3 February Zsuzsanna Jakab, WHO's regional director for Europe, said that countries should take urgent action to control populations of mosquitoes of the Aedes genus, enhance surveillance and detection, step up research and inform people at risk, particularly pregnant women, about mosquito bites.

"Every European country in which Aedes mosquitoes are present can be at risk for the spread of Zika virus disease. A number of travellers infected with Zika have entered Europe, but the disease has not been transmitted further, as the mosquito is still inactive. With the onset of spring and summer, the risk that Zika virus will spread increases," said Jakab.

She added that the virus had to be stopped at "its source."

The Aedes aegypti mosquito is the principal vector for the Zika virus, which has been linked with a cluster of babies born with microcephaly in South America, though the association has not yet been proved. But there are also concerns that the virus could be carried by A albopictus, a mosquito present in southern Europe and which, like other Aedes mosquitoes, carries the dengue fever virus. The European strain of $A$ albopictus can undergo a period of reduced development in the winter months, says WHO.

The European Centre for Disease Prevention and Control said that $A$ albopictus was established in southern Europe, including Spain, France, Italy, and Greece. A aegypti is established in Madeira, where there was an outbreak of dengue fever in 2012, and in southern Russia and Georgia.

A spokeswoman for WHO's regional office said that no link between A albopictus and Zika virus had yet been proved. Previous studies had indicated that $A$ albopictus was a potential vector. "We don't have strong evidence, but we're looking into it," she said.

For all The BMSs latest stories on the Zika virus outbreak see bmj.co/ zika.

Cite this as: BMJ 2016;352:1753

๑ BMJ Publishing Group Ltd 2016 